\title{
Fixed point theorems for some multivalued mappings
}

\author{
Cafer Aydin ${ }^{1}$ and Seher Sultan Sepet ${ }^{2}$ \\ ${ }^{1}$ Department of Mathematics, Kahramanmaraş Sütçü İmam University, Kahramanmaraş, 46040, Turkey \\ ${ }^{2}$ Institute of Science and Technology, Kahramanmaraş Sütçü İmam University, Kahramanmaraş, 46040, Turkey
}

Received: 5 June 2019, Accepted: 15 November 2019

Published online: 26 December 2019.

\begin{abstract}
In this article, we establish some common fixed point theorems for multi-valued mappings satisfying $g$-weak compatible $F$ contraction conditions in complete partial metric spaces. These theorems generalize many previously obtained fixed point results. Also a example is given to illustrate the main theorems.
\end{abstract}

Keywords: Fixed point, $g$-weak compatible, multi-valued mappings.

\section{Introduction}

In 1922 Banach [5], introduced the famous fundamental fixed point theorem, also known as the Banach contraction principle. The Banach contraction principle is the simplest and one of the most adaptable elementary results in fixed point theory. Throughout the years, several extensions and generalizations of this principle have appeared in the literature. Matthews [15], introduced the partial metric spaces and presented a fixed point theorem on partial metric space. Following this various fixed point results were proved in these spaces, for more details, $[1,4,7,8,9,10,12,13,14]$.

In the other part Wardowski [20], indicated the concept of a $F$-contraction mapping and investigated the existence of fixed points for such mappings. Consistent with Wardowski, we represented the $\mathscr{F}$ set of all functions, $F: \mathbb{R}_{+} \rightarrow \mathbb{R}^{-1}$ satisfying the following cases:

(F1) $F$ is strictly increasing. That is, $\alpha<\beta \Rightarrow F(\alpha)<F(\beta)$ for all $\alpha, \beta \in \mathbb{R}_{+}$

(F2) For every sequence $\left\{\alpha_{n}\right\}_{n \in \mathbb{N}}$ in $\mathbb{R}_{+}$we have $\lim _{n \rightarrow \infty} \alpha_{n}=0$ if and only if $\lim _{n \rightarrow \infty} F\left(\alpha_{n}\right)=-\infty$

(F3) There exists a number $k \in(0,1)$ such that $\lim _{\alpha \rightarrow 0^{+}} \alpha^{k} F(\alpha)=0$.

The conclusions of Wardowski became the new attention of several authors (see $[11,16]$ ).

Recently, Nadler [17], introduced the notion of multi-valued contraction mapping and proved well known Banach contraction principle. Many authors followed Nadler's idea and gave their contributions in that sense, see for example [3, 4]. Aydi at al., [4] proved the Banach type fixed point results for set valued mapping in partial metric spaces.

Now, consistent with Aydi et al. [4], we state the following: Let $(X, p)$ be partial metric space. We shall denote $C B^{p}(X)$ the family of all nonempty closed bounded subsets of $X$.

The some main results of this paper were presented in part at the IKSAD 26-28 April 2019 Adana, Turkey.

\footnotetext{
*Corresponding author e-mail: sultanseher20@gmail.com
} 
We recall that partial Hausdorff metric induced by a partial metric on a set $X$ is given by

$$
H_{p}(A, B)=\max \left\{\sup _{x \in A} p(x, B), \sup _{y \in B} p(y, A)\right\}
$$

for every $A, B \in C B^{p}(X)$, where $p(x, B)=\inf \{p(x, y): y \in B\}, \delta_{p}(A, B)=\sup \{p(x, B): x \in A\}, C B^{p}(X)$ is the collection of the closed and bounded subsets of $X$ and $K(X)$ the family of all nonempty compact subsets of $X$. Our results is related to mappings $T: X \rightarrow K^{p}(X)$. Then, we will use the following lemma.

Lemma 1. [2]. Let $(X, p)$ partial metric spaces and A compact subsets of $X$. Then, for $x \in X$, there exists a $\in A$ such that

$$
p(x, a)=p(x, A)
$$

Lemma 2. [4]. Let $A$ and $B$ be nonempty closed and bounded subsets of a partial metric space and $h>1$. Then, for all $a \in A$, there exists $b \in B$ such that

$$
p(a, b) \leq h H_{p}(A, B)
$$

Lemma 3. Let $A$ and $B$ be nonempty closed and bounded subsets of a partial metric space. Then, For any a $\in$,

$$
p(a, B) \leq H_{p}(A, B)
$$

Below, we briefly mention a number of fundamental definitions.

Definition 1. [15]. A partial metric on a nonempty set $X$ is a function $p: X \times X \rightarrow \mathbb{R}^{+}$(nonnegative reals) such that, for all $x, y, z \in X$ :

(p1) $x=y \Leftrightarrow p(x, x)=p(x, y)=p(y, y)\left(T_{0}\right.$-separation axiom),

(p2) $p(x, x) \leq p(x, y)$ (small self-distance axiom),

(p3) $p(x, y)=p(y, x)$ (symmetry),

(p4) $p(x, y) \leq p(x, z)+p(z, y)-p(z, z)$ (modified triangular inequality).

A partial metric space is a pair $(X, p)$ such that $X$ is a nonempty set and $p$ is a partial metric on $X$. It is clear that if $p(x, y)=0$, then, from (p1) and (p2), $x=y$. But if $x=y, p(x, y)$ may not be 0. A basic example of a partial metric space is the pair $\left(\mathbb{R}^{+}, p\right)$, where $p(x, y)=\max \{x, y\}$ for all $x, y \in \mathbb{R}^{+}$. For another example, let I denote the set of all closed intervals $[a, b]$ for any real numbers $a \leq b$. Let $p: I \times I \rightarrow \mathbb{R}^{+}$be the function such that $p([a, b],[c, d])=$ $\max \{b, d\}-\min \{a, c\}$. Then $(I, p)$ is a partial metric space. Other examples of partial metric space which are interesting from a computational point of view may be found in $[6,15]$.

Each partial metric $p$ on $X$ generates a $T_{0}$ topology $\tau_{p}$ on $X$ which has a base as the family open $p$-balls

$$
\left\{B_{p}(x, \varepsilon): x \in X, \varepsilon>0\right\}
$$

where

$$
B_{p}(x, \varepsilon)=\{y \in X: p(x, y)<p(x, x)+\varepsilon\}
$$

for all $x \in X$ and $\varepsilon>0$.

Lemma 4. [15]. Let $(X, p)$ be a complete partial metric space. Then,

(A) If $p(x, y)=0$, then $x=y$.

(B) If $x \neq y$, then $p(x, y)>0$. 
Example 1. [13,19]. Let $(X, d)$ and $(X, p)$ be a metric space and a partial metric space, respectively. Functions $p: X \times X \rightarrow$ $\mathbb{R}^{+}(i \in\{1,2,3\})$ given by

(•) $\rho_{1}(x, y)=d(x, y)+p(x, y)$,

(•) $\rho_{2}(x, y)=d(x, y)+\max \{u(x), u(y)\}$,

(•) $\rho_{3}(x, y)=d(x, y)+a$,

define partial metrics on $X$, where $u: X \rightarrow \mathbb{R}^{+}$is an arbitrary function and $a \geq 0$.

Definition 2. [15]. Let $(X, p)$ be a partial metric space. Then,

(i) a sequence $\left\{x_{n}\right\}$ in a partial metric space $(X, p)$ converges with respect to $\tau_{p}$ to a point $x \in X$ if $p(x, x)=\lim _{n \rightarrow \infty} p\left(x, x_{n}\right)$,

(ii) a sequence $\left\{x_{n}\right\}$ in a partial metric space $(X, p)$ is called a Cauchy sequence if there exists $\lim _{n, m \rightarrow \infty} p\left(x_{n}, x_{m}\right)$ (and is finite),

(iii) a partial metric space $(X, p)$ is said to be complete if every Cauchy sequence $\left\{x_{n}\right\}$ in $X$ converges to a point $x \in X$; that is, $p(x, x)=\lim _{n, m \rightarrow \infty} p\left(x_{n}, x_{m}\right)$.

We present an extension of the notion of $f$-weak compatibility of Pathak [18] on metric space in partial metric space.

Definition 3. Let $(X, p)$ be partial metric space. The mapping $g: X \rightarrow X$ and $T: X \rightarrow C B^{p}(X)$ are g-weak compatible iff $g T x \in C B^{p}(X)$ for all $x \in X$ and the following limits exists and satisfy

(i) $\lim _{n \rightarrow \infty} H_{p}\left(g T x_{n}, T g x_{n}\right) \leq \lim _{n \rightarrow \infty} H_{p}\left(T g x_{n}, T x_{n}\right)$,

(ii) $\lim _{n \rightarrow \infty} p\left(g T x_{n}, g x_{n}\right) \leq \lim _{n \rightarrow \infty} H_{p}\left(T g x_{n}, T x_{n}\right)$,

whenever $\left\{x_{n}\right\}$ is a sequence $X$ such that $T x_{n} \rightarrow M \in C B^{p}(X)$ and $g x_{n} \rightarrow z \in M$.

\section{Main results}

In this section, we give some common fixed point theorems using g-weak compatible $F$ contractive of multi-valued mappings in partial metric space.

Definition 4. Let $(X, p)$ be a complete partial metric space, $g: X \rightarrow X$ and $T: X \rightarrow K^{p}(X)$ be g-weak compatible 1. type $F$ - contraction mappings, if there exists $\tau>0$ such that;

$$
\frac{1}{2} p(g x, T x)<p(g x, g y)
$$

then

$$
\tau+F\left(H_{p}(T x, T y)\right) \leq F(p(g x, g y))
$$

for all $x, y \in X$.

Theorem 1. Let $(X, p)$ be a complete partial metric space and $g, T$-weak compatible 1 . type $F$-contraction continuous mappings. Then there exists a point $z \in X$ such that $g z \in T z$.

Proof. Let $x_{0}$ be an arbitrary point of $X$ and choose $x_{1} \in X$ such that $g x_{1} \in T x_{0}$. This is possible since $T x_{0} \subseteq g(X)$. In general, having chosen $x_{n} \in X$ we choose $x_{n+1} \in X$, so that $y_{n}=g x_{n+1} \in T x_{n}$. Suppose that there exists $n \in \mathbb{N}$ for which 
$y_{n}=y_{n+1}$. We obtain $g x_{n} \in T x_{n}$ and so the proof is complete. Now assume that $n \in \mathbb{N}$ for which $y_{n} \neq y_{n+1}$. Since $T x_{0}$ is compact, from Lemma 1 we obtain that $y_{0} \in T x_{0}$ such that $p\left(g x_{0}, y_{0}\right)=p\left(g x_{0}, T x_{0}\right)>0$. This implies that

$$
\frac{1}{2} p\left(g x_{0}, T x_{0}\right)<p\left(g x_{0}, g x_{1}\right)
$$

From Lemma 3 and condition $(F 1)$, we have

$$
F\left(p\left(g x_{1}, T x_{1}\right)\right) \leq F\left(H_{p}\left(T x_{0}, T x_{1}\right)\right)
$$

By the hypothesis of the theorem, we obtain,

$$
\tau+F\left(p\left(g x_{1}, T x_{1}\right)\right) \leq \tau+F\left(H_{p}\left(T x_{0}, T x_{1}\right)\right) \leq F\left(p\left(g x_{0}, g x_{1}\right)\right) .
$$

Also, since $g x_{1} \in T x_{0}$ and $g x_{2} \in T x_{1}$, we obtain

$$
\tau+F\left(p\left(g x_{1}, g x_{2}\right)\right) \leq F\left(p\left(g x_{0}, g x_{1}\right)\right)
$$

Moreover, $g x_{n+1} \in T x_{n}$ we obtain

$$
\frac{1}{2} p\left(g x_{n}, T x_{n}\right)<p\left(g x_{n}, g x_{n+1}\right)
$$

for all $n \in \mathbb{N}$ and from $(F 1)$ and Lemma 3, we obtain

$$
F\left(p\left(g x_{n}, T x_{n}\right)\right) \leq F\left(H_{p}\left(T x_{n-1}, T x_{n}\right)\right)
$$

for all $n \in \mathbb{N}$. Since (2), we get

$$
\begin{gathered}
\tau+F\left(p\left(g x_{n}, T x_{n}\right)\right) \leq \tau+F\left(H_{p}\left(T x_{n-1}, T x_{n}\right)\right) \leq F\left(p\left(g x_{n-1}, g x_{n}\right)\right), \\
F\left(p\left(g x_{n}, g x_{n+1}\right)\right) \leq F\left(p\left(g x_{n-1}, g x_{n}\right)\right)-\tau \leq F\left(p\left(g x_{n-2}, g x_{n-1}\right)\right)-2 \tau \\
\leq F\left(p\left(g x_{n-3}, g x_{n-2}\right)\right)-3 \tau \cdots \leq F\left(p\left(g x_{0}, g x_{1}\right)\right)-n \tau .
\end{gathered}
$$

Thus, we have

$$
F\left(p\left(g x_{n}, g x_{n+1}\right)\right) \leq F\left(p\left(g x_{0}, g x_{1}\right)\right)-n \tau
$$

for $n=1,2, \ldots$. Let $t_{n}=p\left(g x_{n}, g x_{n+1}\right)$, we get

$$
\lim _{n \rightarrow \infty} F\left(p\left(g x_{n}, g x_{n+1}\right)\right)=\lim _{n \rightarrow \infty} F\left(t_{n}\right)=-\infty
$$

Hence, from $(F 2)$, we obtain $\lim _{n \rightarrow \infty} p\left(g x_{n}, g x_{n+1}\right)=0$. Since $(F 3)$, there exists $k \in(0,1)$ such that $\lim _{n \rightarrow \infty} t_{n}^{k} F\left(t_{n}\right)=0$. Using (5), we have

$$
t_{n}^{k} F\left(t_{n}\right)-t_{n}^{k} F\left(t_{0}\right) \leq-t_{n}^{k} n \tau \leq 0 .
$$


Letting $n \rightarrow \infty$, we get

$$
\lim _{n \rightarrow \infty} t_{n}^{k} n=0
$$

There exist for all $n>n_{1}$ and $n_{1} \in \mathbb{N}$ such that $t_{n}^{k} n \leq 1$. Thus, we have

$$
t_{n} \leq \frac{1}{(n)^{\frac{1}{k}}}
$$

Now, we show that $\left\{g x_{n}\right\}$ is a Cauchy sequence. For any $m, n \in \mathbb{N}$ with $m>n>n_{1}$, we get

$$
\begin{aligned}
p\left(g x_{n}, g x_{m}\right) \leq & p\left(g x_{n}, g x_{n+1}\right)+p\left(g x_{n+1}, g x_{n+2}\right)+\cdots+p\left(g x_{m-1}, g x_{m}\right) \\
& -\left[p\left(g x_{n+1}, g x_{n+1}\right)+p\left(g x_{n+2}, g x_{n+2}\right)+\ldots+p\left(g x_{m-1}, g x_{m-1}\right)\right] \\
= & t_{n}+t_{n+1}+\cdots+t_{m-1}=\sum_{i=n}^{m-1} t_{i} \leq \sum_{i=n}^{\infty} t_{i} \leq \sum_{i=n}^{\infty} \frac{1}{i^{\frac{1}{k}}} .
\end{aligned}
$$

Letting $n \rightarrow \infty$, we have $p\left(g x_{n}, g x_{m}\right) \rightarrow 0$. Thus, $\left\{g x_{n}\right\}$ sequence is a Cauchy sequence. Also, by the completeness of $(X, p)$ there exists $z \in X$ such that

$$
\begin{gathered}
p(z, z)=\lim _{n \rightarrow \infty} p\left(g x_{n}, z\right)=\lim _{n, m \rightarrow \infty} p\left(g x_{n}, g x_{m}\right)=0 . \\
\tau+F\left(H_{p}\left(T x_{n-1}, T x_{n}\right)\right) \leq F\left(p\left(g x_{n-1}, g x_{n}\right)\right) .
\end{gathered}
$$

These imply that $\left\{T x_{n}\right\}$ is a Cauchy sequence in the complete partial metric space $\left(K^{p}(X), H_{p}\right)$. Thus, let $T x_{n} \rightarrow M \in K^{p}(X)$. Now we have

$$
\begin{aligned}
p(z, M) & \leq p\left(z, g x_{n}\right)+p\left(g x_{n}, M\right)-p\left(g x_{n}, g x_{n}\right) \\
& \leq p\left(z, g x_{n}\right)+p\left(T x_{n-1}, M\right) \rightarrow 0 \quad(\text { as } n \rightarrow \infty) .
\end{aligned}
$$

Since $M$ is closed, we obtain $z \in M$. $g$-weak compatibility and the continuity of $g$ and $T$ implies that

$$
\begin{gathered}
H_{p}(g M, T z) \leq H_{p}(T z, M), \\
p(g z, z) \leq H_{p}(T z, M) .
\end{gathered}
$$

Now we have

$$
\begin{aligned}
p(g z, T z) & \leq p\left(g z, g g x_{n+1}\right)+p\left(g g x_{n+1}, T z\right)-p\left(g g x_{n+1}, g g x_{n+1}\right) \\
& \leq p\left(g z, g g x_{n+1}\right)+H_{p}\left(g T x_{n}, T z\right) \\
& \leq p\left(g z, g g x_{n+1}\right)+H_{p}\left(g T x_{n}, T g x_{n}\right)+H_{p}\left(T g x_{n}, T z\right)-\inf _{z \in T g x_{n}}\{p(z, z)\} .
\end{aligned}
$$

Letting $n \rightarrow \infty$ in the above inequality, we obtain

$$
p(g z, T z) \leq H_{p}(T z, M) .
$$


Now using (2), we have

$$
\tau+F\left(H_{p}\left(T x_{n}, T z\right)\right) \leq F\left(p\left(g x_{n}, g z\right)\right)
$$

Letting $n \rightarrow \infty$ in the above inequality, we obtain

$$
\tau+F\left(H_{p}(M, T z)\right) \leq F(p(z, g z))
$$

Using (10) and (F1), we obtain

$$
\tau+F\left(H_{p}(M, T z)\right) \leq F(p(z, g z)) \leq F\left(H_{p}(T z, M)\right)
$$

Since $\tau>0$, we obtain $H_{p}(T z, M)=0$. Then $p(g z, T z)=0, g z \in T z$ since $T$ closed.

Corollary 1. Let $(X, p)$ be a complete partial metric space and $T: X \rightarrow K^{p}(X)$ be $F$ - contraction mappings, if there exists $\tau>0$ such that;

$$
\frac{1}{2} p(x, T x)<p(x, y)
$$

then

$$
\tau+F\left(H_{p}(T x, T y)\right) \leq F(p(x, y))
$$

for all $x, y \in X$.

Definition 5. Let $(X, p)$ be a complete partial metric space, $g: X \rightarrow X$ and $T: X \rightarrow K^{p}(X)$ be g-weak compatible 2. type $F$ - contraction mappings, if there exists $\tau>0$ such that;

$$
\frac{1}{2} p(g x, T x)<p(g x, g y)
$$

then

$$
\tau+F\left(H_{p}(T x, T y)\right) \leq \alpha F(p(g x, g y))+\beta F(p(g x, T x))+\gamma F(p(g y, T y))
$$

for all $x, y \in X$ where $\alpha, \beta \in(0,1]$ are real numbers such that $0 \leq \gamma<1$ and $\alpha+\beta+\gamma=1$.

Theorem 2. Let $(X, p)$ be a complete partial metric space and $g, T$-weak compatible 2. type F-contraction continuous mappings. Then there exists a point $z \in X$ such that $g z \in T z$.

Proof. Let $x_{0}$ be an arbitrary point of $X$ and choose $x_{1} \in X$ such that $g x_{1} \in T x_{0}$. This is possible since $T x_{0} \subseteq g(X)$. In general, having chosen $x_{n} \in X$ we choose $x_{n+1} \in X$, so that $y_{n}=g x_{n+1} \in T x_{n}$. Suppose that there exists $n \in \mathbb{N}$ for which $y_{n}=y_{n+1}$. We obtain $g x_{n} \in T x_{n}$ and so the proof is complete. Now assume that $n \in \mathbb{N}$ for which $y_{n} \neq y_{n+1}$. Since $T x_{0}$ is compact, from Lemma 1, we obtain that $y_{0} \in T x_{0}$ such that $p\left(g x_{0}, y_{0}\right)=p\left(g x_{0}, T x_{0}\right)>0$. This implies that

$$
\frac{1}{2} p\left(g x_{0}, T x_{0}\right)<p\left(g x_{0}, g x_{1}\right)
$$

From Lemma 3 and condition $(F 1)$, we have

$$
F\left(p\left(g x_{1}, T x_{1}\right)\right) \leq F\left(H_{p}\left(T x_{0}, T x_{1}\right)\right)
$$


By the hypothesis of the theorem, we obtain,

$$
\tau+F\left(p\left(g x_{1}, T x_{1}\right)\right) \leq \tau+F\left(H_{p}\left(T x_{0}, T x_{1}\right)\right) \leq \alpha F\left(p\left(g x_{0}, g x_{1}\right)\right)+\beta F\left(p\left(g x_{0}, T x_{0}\right)\right)+\gamma F\left(p\left(g x_{1}, T x_{1}\right)\right) .
$$

Also, since $g x_{1} \in T x_{0}$ and $g x_{2} \in T x_{1}$, we obtain

$$
\tau+F\left(p\left(g x_{1}, g x_{2}\right)\right) \leq \alpha F\left(p\left(g x_{0}, g x_{1}\right)\right)+\beta F\left(p\left(g x_{0}, g x_{1}\right)\right)+\gamma F\left(p\left(g x_{1}, g x_{2}\right)\right)
$$

and

$$
\tau+(1-\gamma) F\left(p\left(g x_{1}, g x_{2}\right)\right) \leq(\alpha+\beta) F\left(p\left(g x_{0}, g x_{1}\right)\right) .
$$

Since $\alpha+\beta+\gamma=1$, we get

$$
F\left(p\left(g x_{1}, g x_{2}\right)\right) \leq F\left(p\left(g x_{0}, g x_{1}\right)\right)-\frac{\tau}{\alpha+\beta}
$$

Moreover, $g x_{n+1} \in T x_{n}$ we obtain

$$
\frac{1}{2} p\left(g x_{n}, T x_{n}\right)<p\left(g x_{n}, g x_{n+1}\right)
$$

for all $n \in \mathbb{N}$. From $(F 1)$ and Lemma 3, we obtain

$$
F\left(p\left(g x_{n}, T x_{n}\right)\right) \leq F\left(H_{p}\left(T x_{n-1}, T x_{n}\right)\right)
$$

for all $n \in \mathbb{N}$. Since (14), we get

$$
\tau+F\left(p\left(g x_{n}, T x_{n}\right)\right) \leq \tau+F\left(H_{p}\left(T x_{n-1}, T x_{n}\right)\right) \leq \alpha F\left(p\left(g x_{n-1}, g x_{n}\right)\right)+\beta F\left(p\left(g x_{n-1}, T x_{n-1}\right)\right)+\gamma F\left(p\left(g x_{n}, T x_{n}\right)\right),
$$

and

$$
\begin{gathered}
\tau+(1-\gamma) F\left(p\left(g x_{n}, g x_{n+1}\right)\right) \leq(\alpha+\beta) F\left(p\left(g x_{n-1}, g x_{n}\right)\right) \\
F\left(p\left(g x_{n}, g x_{n+1}\right)\right) \leq F\left(p\left(g x_{n-1}, g x_{n}\right)\right)-\frac{\tau}{\alpha+\beta} \\
\leq F\left(p\left(g x_{n-2}, g x_{n-1}\right)\right)-\frac{2 \tau}{\alpha+\beta} \\
\leq F\left(p\left(g x_{n-3}, g x_{n-2}\right)\right)-\frac{3 \tau}{\alpha+\beta} \\
\vdots \\
\leq F\left(p\left(g x_{0}, g x_{1}\right)\right)-\frac{n \tau}{\alpha+\beta} .
\end{gathered}
$$

Thus, we have

$$
F\left(p\left(g x_{n}, g x_{n+1}\right)\right) \leq F\left(p\left(g x_{0}, g x_{1}\right)\right)-\frac{n \tau}{\alpha+\beta}
$$


for $n=1,2, \ldots$. Let $t_{n}=p\left(g x_{n}, g x_{n+1}\right)$, we get

$$
\lim _{n \rightarrow \infty} F\left(p\left(g x_{n}, g x_{n+1}\right)\right)=\lim _{n \rightarrow \infty} F\left(t_{n}\right)=-\infty .
$$

Hence, from $(F 2)$, we obtain $\lim _{n \rightarrow \infty} p\left(g x_{n}, g x_{n+1}\right)=0$. Since $(F 3)$, there exists $k \in(0,1)$ such that $\lim _{n \rightarrow \infty} t_{n}^{k} F\left(t_{n}\right)=0$. Using (18), we have

$$
t_{n}^{k} F\left(t_{n}\right)-t_{n}^{k} F\left(t_{0}\right) \leq-t_{n}^{k} \frac{n \tau}{\alpha+\beta} \leq 0
$$

Letting $n \rightarrow \infty$, we get

$$
\lim _{n \rightarrow \infty} t_{n}^{k} \frac{n}{\alpha+\beta}=0
$$

There exist for all $n>n_{1}$ and $n_{1} \in \mathbb{N}$ such that $t_{n}^{k} \frac{n}{\alpha+\beta} \leq 1$. Thus, we have

$$
t_{n} \leq \frac{1}{\left(\frac{n}{\alpha+\beta}\right)^{\frac{1}{k}}} .
$$

Now, we show that $\left\{g x_{n}\right\}$ is a Cauchy sequence. For any $m, n \in \mathbb{N}$ with $m>n>n_{1}$, we get

$$
\begin{aligned}
p\left(g x_{n}, g x_{m}\right) \leq & p\left(g x_{n}, g x_{n+1}\right)+p\left(g x_{n+1}, g x_{n+2}\right)+\cdots+p\left(g x_{m-1}, g x_{m}\right) \\
& -\left[p\left(g x_{n+1}, g x_{n+1}\right)+p\left(g x_{n+2}, g x_{n+2}\right)+\ldots+p\left(g x_{m-1}, g x_{m-1}\right)\right] \\
= & t_{n}+t_{n+1}+\cdots+t_{m-1}=\sum_{i=n}^{m-1} t_{i} \leq \sum_{i=n}^{\infty} t_{i} \leq \sum_{i=n}^{\infty} \frac{1}{i^{\frac{1}{k}}} .
\end{aligned}
$$

Letting $n \rightarrow \infty$, we have $p\left(g x_{n}, g x_{m}\right) \rightarrow 0$. Thus, $\left\{g x_{n}\right\}$ sequence is a Cauchy sequence. Also, by the completeness of $(X, p)$ there exists $z \in X$ such that

$$
\begin{gathered}
p(z, z)=\lim _{n \rightarrow \infty} p\left(g x_{n}, z\right)=\lim _{n, m \rightarrow \infty} p\left(g x_{n}, g x_{m}\right)=0 . \\
\tau+F\left(H_{p}\left(T x_{n-1}, T x_{n}\right)\right) \leq \alpha F\left(p\left(g x_{n-1}, g x_{n}\right)\right)+\beta F\left(p\left(g x_{n-1}, g x_{n}\right)\right)+\gamma F\left(p\left(g x_{n}, g x_{n+1}\right)\right) .
\end{gathered}
$$

These imply that $\left\{T x_{n}\right\}$ is a Cauchy sequence in the complete partial metric space $\left(K^{p}(X), H_{p}\right)$. Thus, let $T x_{n} \rightarrow M \in K^{p}(X)$. Now we have

$$
p(z, M) \leq p\left(z, g x_{n}\right)+p\left(g x_{n}, M\right)-p\left(g x_{n}, g x_{n}\right) \leq p\left(z, g x_{n}\right)+p\left(T x_{n-1}, M\right) \rightarrow 0 \quad(\text { as } n \rightarrow \infty) .
$$

Since $M$ is closed, we obtain $z \in M . g$-weak compatibility and the continuity of $g$ and $T$ implies that

$$
\begin{gathered}
H_{p}(g M, T z) \leq H_{p}(T z, M), \\
p(g z, z) \leq H_{p}(T z, M) .
\end{gathered}
$$


Now we have

$$
\begin{aligned}
p(g z, T z) & \leq p\left(g z, g g x_{n+1}\right)+p\left(g g x_{n+1}, T z\right)-p\left(g g x_{n+1}, g g x_{n+1}\right) \\
& \leq p\left(g z, g g x_{n+1}\right)+H_{p}\left(g T x_{n}, T z\right) \\
& \leq p\left(g z, g g x_{n+1}\right)+H_{p}\left(g T x_{n}, T g x_{n}\right)+H_{p}\left(T g x_{n}, T z\right)-\inf _{z \in T g x_{n}}\{p(z, z)\} .
\end{aligned}
$$

Letting $n \rightarrow \infty$ in the above inequality, we obtain

$$
p(g z, T z) \leq H_{p}(T z, M)
$$

Now using (14), we have

$$
\begin{aligned}
\tau+F\left(H_{p}\left(T x_{n}, T z\right)\right) & \leq \alpha F\left(p\left(g x_{n}, g z\right)\right)+\beta F\left(p\left(g x_{n}, T x_{n}\right)\right)+\gamma F(p(g z, T z)), \\
\tau+F\left(H_{p}(M, T z)\right) & \leq \alpha F(p(z, g z))+\beta F(p(z, M))+\gamma F(p(g z, T z)), \\
\tau+F\left(H_{p}(M, T z)\right) & \leq(\alpha+\gamma) F\left(H_{p}(T z, M)\right) .
\end{aligned}
$$

Since $\tau>0$, and $\alpha+\gamma<1$, we obtain $H_{p}(T z, M)=0$. Then $p(g z, T z)=0, g z \in T z$ since $T$ closed.

Corollary 2. Let $(X, p)$ be a complete partial metric space and $T: X \rightarrow K^{p}(X)$ be $F$ - contraction mappings, if there exists $\tau>0$ such that;

$$
\frac{1}{2} p(x, T x)<p(x, y)
$$

then

$$
\tau+F\left(H_{p}(T x, T y)\right) \leq \alpha F(p(x, y))+\beta F(p(x, T x))+\gamma F(p(y, T y))
$$

for all $x, y \in X$ where $\alpha, \beta \in(0,1]$ are real numbers such that $0 \leq \gamma<1$ and $\alpha+\beta+\gamma=1$.

Example 2. Let $X=[0, \infty)$ and define $p: X \times X \rightarrow \mathbb{R}^{+}$by $(X, p)$ be a partial metric space where $p(x, y)=|x-y|+\max \{x, y\}$ for all $x, y \in X$. Then $(X, p)$ is a complete partial metric space. We define $g: X \rightarrow X$, $T: X \rightarrow K^{p}(X)$ a multivalued mapping where $g x=x$ and $T(x)=\left[0, \frac{x}{8}\right]$ for all $x \in X$. Let $F(\alpha)=-\frac{1}{\alpha}$, and $y=\frac{x}{8} \in T(x)$ for all $x \in X$. Then, we have,

$$
\begin{aligned}
\frac{1}{2} p\left(x,\left[0, \frac{x}{8}\right]\right) & <p\left(x, \frac{x}{8}\right) \\
\frac{1}{2}\left(\left|x-\left[0, \frac{x}{8}\right]\right|+\max \left\{x,\left[0, \frac{x}{8}\right]\right\}\right) & <\left(\left|x-\frac{x}{8}\right|+\max \left\{x, \frac{x}{8}\right\}\right) \\
\frac{1}{2}\left(x+\frac{7 x}{8}\right) & <x+\frac{7 x}{8}
\end{aligned}
$$

that is, in (1) is satisfied.

Now, we may to show that satisfying in (2) of the Theorem 1.

$$
\begin{gathered}
\tau+F\left(H_{p}(T x, T y)\right) \leq F(p(g x, g y)) \\
\tau-\frac{1}{H_{p}(T x, T y)} \leq-\frac{1}{p(g x, g y)}
\end{gathered}
$$




$$
H_{p}(T x, T y)=H_{p}\left(\left[0, \frac{x}{8}\right],\left[0, \frac{x}{64}\right]\right)=\max \left\{\delta_{p}\left(\left[0, \frac{x}{8}\right],\left[0, \frac{x}{64}\right]\right), \delta_{p}\left(\left[0, \frac{x}{64}\right],\left[0, \frac{x}{8}\right]\right)\right\}
$$

Then, we have

$$
\delta_{p}\left(\left[0, \frac{x}{8}\right],\left[0, \frac{x}{64}\right]\right)=\sup \left\{p\left(a,\left[0, \frac{x}{64}\right]\right): a \in\left[0, \frac{x}{8}\right]\right\}
$$

Here, let $a \in\left[0, \frac{x}{64}\right]$, then $\sup p\left(a,\left[0, \frac{x}{64}\right]\right)=0$. Also, let $a \in\left[0, \frac{x}{8}\right] \backslash\left[0, \frac{x}{64}\right]$, then $\sup p\left(a,\left[0, \frac{x}{64}\right]\right)=\frac{7 x}{64}$. Hence, $\delta_{p}\left(\left[0, \frac{x}{64}\right],\left[0, \frac{x}{8}\right]\right)=\sup \left\{p\left(b,\left[0, \frac{x}{8}\right]\right): b \in\left[0, \frac{x}{64}\right]\right\}=0$. Also, we have $\delta_{p}\left(\left[0, \frac{x}{8}\right],\left[0, \frac{x}{64}\right]\right)=\frac{7 x}{64}$. Therefore,

$$
H_{p}(T x, T y)=\max \left\{0, \frac{7 x}{64}\right\}=\frac{7 x}{64} .
$$

Also, we have,

$$
p(g x, g y)=|x-y|+\max \{x, y\}=\left|x-\frac{x}{8}\right|+\max \left\{x, \frac{x}{8}\right\}=\frac{7 x}{8}+x=\frac{15 x}{8}
$$

also using (26), we obtain

$$
\begin{gathered}
\tau \leq \frac{1}{\frac{7 x}{64}}-\frac{1}{\frac{15 x}{8}} \\
\tau \leq \frac{64}{7 x}-\frac{8}{15 x}=\frac{904}{105 x} .
\end{gathered}
$$

Obviously, this is satisfying the condition of Theorem 1.

\section{Competing interests}

The authors declare that they have no competing interests.

\section{Authors' contributions}

All authors have contributed to all parts of the article. All authors read and approved the final manuscript.

\section{References}

[1] Abdeljawad, T., Karapınar, E., Taş, K. A generalized contraction principle with control functions on partial metric spaces. Computers Mathematics with Applications, 63, (2012), 716-719.

[2] Altun, I., Sola, F., Şimşek, H. Generalized contractions on partial metric spaces. Topology and its Applications, 157:18, (2010), 2778-2785.

[3] Assad, N. and Kirk, W. Fixed point theorems for set-valued mappings of contractive type. Pacific J. Math. 43 (1972) no.3, $553-562$.

[4] Aydi, H., Abbas, M., Vetro, C. Partial Hausdorff metric and Nadler's fixed point theorem on partial metric spaces. Topol Appl., 159:14, (2012), 3234-3242.

[5] Banach, S. Surles operations dansles ensembles abstracits et leur application aux equations integrales. Fund. Math., 3:1, (1922), 133-181.

[6] Escardo, M.H. PCF Extended with real numbers. Theor. Comput. Sci., 162:1, (1996), 79-115. 
[7] Karapınar, E. A new non-unique fixed point theorem. Journal of Applied Functional Analysis, 7:1-2, (2012), 92-97.

[8] Karapınar, E. A note on common fixed point theorems in partial metric spaces. Miskolc Math. Notes, 12:2, (2011), $185-191$.

[9] Karapınar, E. Ciric types nonunique fixed point theorems on partial metric spaces. Journal of nonlinear science and Applications, 5, (2012), 74-83.

[10] Karapınar, E. Weak $f$-contraction on partial metric spaces. J. Comput. Anal. Appl., 14, (2012), 206-210.

[11] Karapınar, E., Piri, H., Alsulami, H.H. Fixed points of modified F-contractive mappings in complete metric-like spaces. J. Funct Spaces, (2015), Article ID: 270971.

[12] Karapınar, E., Erhan, I.M. Fixed point theorems for operators on partial metric spaces. Appl. Math. Lett., 24:11, (2011) $1900-1904$.

[13] Karapınar, E., Shobkolaei, N., Sedghi, S. Vaezpour, S.M. A common fixed point theorem for cyclic operators on partial metric space. Filomat 26:2, (2012), 407-414.

[14] Karapınar, E., Romaguera, S. Nonunique fixed point theorems in partial metric spaces. Filomat 27:7, (2013), 1305-1314.

[15] Matthews, S.G. Partial metric topology. Annals of the New York Academi of Sciences, 728, (1994) 183-197.

[16] Minak, G. Helvac1, A., Altun, I. Ciric type generalized F-contractions on complete metric spaces and fixed point results. Filomat, 28:6, (2014), 1143-1151.

[17] Nadler, S.B. Multivalued contraction mappings. Pasific J. Math., 30:2, (1969), 475-488.

[18] Pathak, H.K. Fixed points for weak compatible multi-valued and single-valued mapping. Acta Math. Hunger., 67:1-2, (1995), 69-78.

[19] Shobkolaei, N., Vaezpour, S.M., Sedghi, S. A common fixed point theorem on ordered partial metric spaces. J. Basic. Appl. Sci. Res. 1:12, (2011), 3433-3439.

[20] Wardowski, D. Fixed Point of a new type of contactive mappings in complete metric spaces. Fixed Point Theory and Applications, 94, (2012), Article number: 94(2012). 